\title{
Operando X-ray Tomographic Microscopy Imaging of HT-PEFC: A Comparative Study of Phosphoric Acid Electrolyte Migration
}

\author{
S. H. Eberhardt, ${ }^{\text {a,* }}$ F. Marone, ${ }^{\text {b }}$ M. Stampanoni, ${ }^{\text {b,c }}$ F. N. Büchi, ${ }^{\text {a,z }}$ and T. J. Schmidtt ${ }^{\mathrm{a}, \mathrm{d}, * *}$ \\ ${ }^{a}$ Electrochemistry Laboratory, Paul Scherrer Institut, 5232 Villigen PSI, Switzerland \\ ${ }^{b}$ Swiss Light Source, Paul Scherrer Institut, 5232 Villigen PSI, Switzerland \\ ${ }^{c}$ Institute for Biomedical Engineering, ETH Zürich, 8092 Zürich, Switzerland \\ ${ }^{d}$ Laboratory of Physical Chemistry, ETH Zürich, 8093 Zürich, Switzerland
}

\begin{abstract}
Synchrotron based X-ray tomographic microscopy was used to image the redistribution of phosphoric acid in HT-PEFC due to electrolyte migration from cathode to anode. The acid migration rate, transference number of the hydrogen phosphate ion and flooding of the anode gas diffusion layer (GDL) was analyzed for MEAs with different membrane acid doping levels (24-36 $\mathrm{mgcm}^{-2}$ ) and membrane materials (imbibed $m$-polybenzimidazole (PBI) and polyphosphoric acid (PPA) processed $p$-PBI). The most influential factors for the acid migration rate are current density and the amount of free acid in the membrane. High doping level of the membrane and current density above $0.4 \mathrm{~A} \mathrm{~cm}^{-2}$ significantly increase the migration rate. From the migration rates apparent transference numbers for the hydrogen phosphate anions in the order $10^{-5}$ to $10^{-4}$ are calculated at the high current densities. Besides the membrane properties, also the influence of the microstructure of the porous transport layers was analyzed. Most probably cracks in the catalyst and microporous layers facilitate the migration of acid into the anode GDL.

(c) The Author(s) 2016. Published by ECS. This is an open access article distributed under the terms of the Creative Commons Attribution 4.0 License (CC BY, http://creativecommons.org/licenses/by/4.0/), which permits unrestricted reuse of the work in any medium, provided the original work is properly cited. [DOI: 10.1149/2.0801608jes] All rights reserved.
\end{abstract}

Manuscript submitted April 12, 2016; revised manuscript received May 18, 2016. Published June 2, 2016. This was Paper 1420 presented at the Phoenix, Arizona, Meeting of the Society, October 11-15, 2015.

High temperature polymer electrolyte fuel cells (HT-PEFC) are operating at temperatures up to $200^{\circ} \mathrm{C}$ using phosphoric acid (PA) doped polybenzimidazole (PBI) based membranes. This fuel cell technology has a range of beneficial properties. At the higher operating temperatures, the tolerance to fuel gas impurities increases significantly and operation with $\mathrm{CO}$ levels of up to $3 \%$ and $\mathrm{H}_{2} \mathrm{~S}$ up to $10 \mathrm{ppm}$ can be achieved. ${ }^{1,2}$ Consequently, a fuel processing unit can more easily be thermally integrated into the fuel cell system and used for reforming hydrocarbon-based fuels in the absence of an additional selective $\mathrm{CO}$ oxidation gas clean-up step. Furthermore, phosphoric acid exhibits comparable proton conductivity to typical PFSA-type membranes ${ }^{3}$ without the need of additional gas humidification due to a fast proton hopping mechanism. ${ }^{4}$ At a cell temperature of $160^{\circ} \mathrm{C}$ the higher value waste heat is more easily used than with standard low temperature PEFC technology, therefore HT-PEFC have a significant potential for stationary combined heat and power applications (CHP).

The advantageous characteristics of HT-PEFC are based on the physico-chemical properties of the phosphoric acid electrolyte, such as high conductivity due a fast Grotthus like charge transport ${ }^{4}$ and low PA vapor pressure. However, understanding of the degradation mechanisms related to PA volume variations due to concentration changes, ${ }^{5}$ and redistribution of phosphoric acid in the membrane electrode assembly (MEA) is still limited. Additionally, the interaction of the PBI polymer backbone with PA, the acid doping level ${ }^{6-8}$ as well as the membrane synthesis method have a significant influence on properties such as conductivity, mechanical stability.

Since phosphoric acid is not covalently bound to the polymer structure of the membrane, a minor part of the ionic current is also carried by the hydrogen phosphate anions, which have a have a small, but finite transference number. This has already been reported for phosphoric acid fuel cells (PAFC) where the phosphoric acid is confined in a silicon carbide matrix ${ }^{9}$ and has recently been also been shown for cells with PBI membranes produced by the polyphosphoric acid (PPA) process. ${ }^{10}$ These membrane systems exhibit extensive phosphoric acid migration from cathode to anode at high current density. Electrolyte migration has a range of potential implications for fuel cell degradation (reversible and irreversible) such as loss of electrolyte from the MEA resulting in increased membrane resistance, decreased per-

\footnotetext{
*Electrochemical Society Student Member.

**Electrochemical Society Member

${ }^{\mathrm{z}}$ E-mail: felix.buechi@psi.ch
}

formance and reduced lifetime. Under reformate operation, with low hydrogen partial pressure, the occupation of pores in the anode gas diffusion layer (GDL) by phosphoric acid is expected to also influence fuel cell performance by mass transport limitations.

Studying the movement and redistribution of phosphoric acid during fuel cell operation is a difficult task, because it needs access into and through the opaque layers of the fuel cell and MEA materials. Electrochemical impedance spectroscopy (EIS) has been successfully applied to HT-PEFC to gain insight into changing proton conductivity but no direct information about PA location can derived. ${ }^{11,12}$ Operando X-ray imaging, however, a proven tool for characterization of the water distribution in low temperature PEFC (LT-PEFC), ${ }^{13-15}$ has also demonstrated the potential as diagnostic tool for imaging the phosphoric acid electrolyte in HT-PEFC..$^{10,11,16-21}$

In this work, operando X-ray tomographic microscopy (XTM) is used to image the electrolyte redistribution as a function of membrane material (conventional film casted $m-\mathrm{PBI}^{22}$ and PPA processed $p$-PBI membranes ${ }^{23}$ ), electrolyte loading and current density.

\section{Experimental}

General.-For all experiments, a carbon paper gas diffusion layer (GDL) (proprietary material by SGL Carbon SE) including a microporous layer (MPL) coated with a catalyst layer based on $\mathrm{Pt} / \mathrm{Vulcan}$ $\mathrm{XC}-72$ supported catalyst $\left(1 \mathrm{mg}_{\mathrm{Pt}} \mathrm{cm}^{-2}\right)$ was used on cathode and anode. The influence of membrane material was tested by comparing a conventional membrane cast from a dimethyl acetamide (DMAc) organic solvent $(m-\mathrm{PBI})$ and a BASF Celtec membrane ( $p$-PBI) produced by the PPA-process. The two membrane systems are hereafter referred to as $m$-PBI and $p$-PBI for the sake of simplicity.

Operando imaging of the phosphoric acid redistribution was performed using a specially designed cell, developed for imaging the water distribution in low temperature PEFC. ${ }^{14}$ It was slightly redesigned to sustain the higher operating temperatures in HT-PEFC imaging. The cell housing consists of Vespel, due to its high thermal stability and X-ray transmittance. The circular flow field design $(\varnothing 6 \mathrm{~mm})$ has three parallel channels $(0.5 \mathrm{~mm}$ width and 0.3 $\mathrm{mm}$ depth) and consists of pyrolytically surface treated and sealed graphite (proprietary surface treatment by POCO Graphite, USA) to prevent phosphoric acid uptake. The circular active area of the MEA is $0.2 \mathrm{~cm}^{2}$. A $320 \mu \mathrm{m}$ thick perfluoroalkoxy alkane (PFA) sealing gasket was used as hard stop on anode and cathode to define GDL compression. 
Phosphoric acid migration is quantified by introducing an apparent transference number which is given by Eq. 1:

$$
t_{\mathrm{H} 2 \mathrm{PO} 4-}^{-}=\frac{i^{-}}{i^{-}+i^{+}}
$$

where $i^{-}$is the current carried by hydrogen phosphate anion and $i^{+}$ the current carried by the proton. The sum of both is equivalent to the charge carried by the electrons in the external electric circuit of the fuel cell. Due to overlapping processes, after protonation of the phosphate anion in the anode, only a fraction of the acid will migrate into the GDL, the rest will diffuse back from anode to cathode, no accurate and direct determination of the transference number is thus possible. Therefore only an apparent transference number can be given. This number is determined from the sections of linear increase of the acid found in the anode GDL (see Figure 3b below) where the migration rate observed (in terms of mole $\mathrm{s}^{-1} \mathrm{~cm}^{-2}$ ) is related to the current density and the respective fraction defined as the apparent transference number. This apparent number of course includes all overlaying effects, and is in any case lower than the effective transference number.

Experimental design.-A current step protocol, summarized in Table I, was used. Gas flow rates were set to $10 \mathrm{ml} \mathrm{min}^{-1} \mathrm{H}_{2}$ and $200 \mathrm{ml} \mathrm{min}-1 \mathrm{O}_{2}$. The excess oxygen and hydrogen levels guarantee differential operating conditions with minimal gradients along the channels. To prevent membrane drying and shrinking, anode and cathode feed were humidified at room temperature. The cell temperature was fixed to $160^{\circ} \mathrm{C}$ for all experiments.

Sample preparation.-The pristine (i) $p$ - $\mathrm{PBI}$ membrane material was supplied by BASF SE, the reduced acid loading of the (ii) $p$-PBI membrane (see Table II) was adjusted by immersing the pristine (i) $p$-PBI membrane material in $36 \mathrm{wt} \% \mathrm{H}_{3} \mathrm{PO}_{4}$ for seven days. The acid loading of the (iii) $m$-PBI membrane was adjusted by immersing the casted polymer film in $85 \mathrm{wt} \% \mathrm{PA}$, accordingly. The resulting PA loading was determined by immersion of the membrane in deionized water overnight and measuring the phosphoric acid concentration in the supernatant solution by ion chromatography (IC) (Metrohm 882 Compact IC plus System; Metrosepp A Supp 5150 anion separation column). For MEAs with a $m$-PBI membrane, an additional acid loading in each of the two electrodes was necessary to achieve satisfying electrochemical performance. This was performed by preparing a $50 / 50 \mathrm{vol} \%$ of $85 \mathrm{wt} \% \mathrm{H}_{3} \mathrm{PO}_{4} /$ acetone mixture and transferring 30 $\mu l$ of the mixture onto the $0.2 \mathrm{~cm}^{2}$ electrode with a pipette. These GDEs were subsequently dried at $60^{\circ} \mathrm{C}$ for $2 \mathrm{~h}$ and residual liquid removed. This increased the total acid loading of the MEA to 32 $\mathrm{mg}_{\mathrm{H} 3 \mathrm{PO} 4} \mathrm{~cm}^{-2}\left(24 \mathrm{mg}_{\mathrm{H} 3 \mathrm{PO} 4} \mathrm{~cm}^{-2}\right.$ membrane and $4 \pm 1 \mathrm{mg}_{\mathrm{H} 3 \mathrm{PO} 4} \mathrm{~cm}^{-2}$ each electrode).

For preparation of the MEAs, the membranes were sandwiched in between the gas diffusion electrodes described above. This was performed by a hot pressing step at $140^{\circ} \mathrm{C}$ for $30 \mathrm{~s}$. Compression was performed at constant gap by using $800 \mu \mathrm{m}$ spacers for Celtec membranes and $600 \mu \mathrm{m}$ spacers for film casted membranes.

The tested MEA materials and resulting PA loadings are given in Table II. Phosphoric acid consists of a mixture of orthophosphoric acid $\mathrm{H}_{3} \mathrm{PO}_{4}, \mathrm{H}_{2} \mathrm{O}$ and polyphosphoric acid, the condensation product of $\mathrm{H}_{3} \mathrm{PO}_{4}$. The ratio of the various products is determined by temperature and water partial pressure. For the sake of simplicity PA subsequently refers to a mixture of $\mathrm{H}_{3} \mathrm{PO}_{4} / \mathrm{H}_{2} \mathrm{O}$ and is quantified as wt $\%$ of $\mathrm{H}_{3} \mathrm{PO}_{4}$.

X-ray imaging.-Synchrotron based X-ray tomographic microscopy (XTM) was performed at the TOMCAT (TOmographic Microscopy and Coherent rAdiology experimenTs) beamline of the Swiss Light Source. ${ }^{24}$ During image acquisition a total of 2001 projections were acquired $\left(180^{\circ}\right.$ sample rotation; $0.09^{\circ}$ step angle; samplescintillator distance $\approx 10 \mathrm{~mm}$ ) at a beam energy of $20 \mathrm{keV}$. The exposure time for each projection was $13 \mathrm{~ms}$, resulting in a total acquisition time for each tomographic scan of $26 \mathrm{~s}$. Projections were reconstructed using an efficient algorithm based on a Fourier method. ${ }^{25}$ The sCMOS camera (PCO.edge) had a chip size of $2560 \times 2160$ pixels and the resulting voxel size in the tomographic image was $2.3 \mu \mathrm{m}$. All tomograms were flat- and darkfield corrected. The reconstructed slices were saved in 16-bit TIFF format using constant minimum and maximum grayscale level values for all scans.

$\mu \mathrm{CT}$ measurements were performed using a Phoenix nanotom $\mathrm{m}$ (GE Measurement \& Control). For this measurement a GDE (GDL, MPL and Pt/Vulcan XC-72 supported platinum catalyst electrode; assembled uncompressed in the operando cell) was imaged using an acceleration voltage of $75 \mathrm{kV}$ and $200 \mu \mathrm{A}$. During the $360^{\circ}$ sample rotation, 2500 projections were recorded. For each projection, three images were recorded and averaged. The exposure time for each projection was set to $500 \mathrm{~ms}$. The detector is a GE DXR detector $(3072 \times 2400$ pixels $)$. Using a 28 fold magnification, a final pixel size of $3.5 \mu \mathrm{m}$ was achieved. Reconstruction is based on a cone beam filtered back projection algorithm using the phoenix datos $\mid \mathrm{x}$ 2.3.0 reconstruction software (GE Measurement \& Control).

Image processing.-To deduce quantitative information from the reconstructed data sets, segmentation of the phosphoric acid and the carbon phase was performed independently, using a combination of the open source software Fiji (ImageJ) and MATLAB. Due to the absence of PA electrolyte on the cathode side, only the GDL and flow field of the anode were processed. Segmenting phosphoric acid involves four steps. First, a median filter $(2 \mathrm{D}, 3 \mathrm{px})$ was applied to reduce unstructured background noise followed by an anisotropic diffusion $\operatorname{step}^{26}(\kappa=2000-10000)$ using MATLAB, to homogenize the grayscale value of phosphoric acid droplets. Subsequently, a manual threshold window was applied to binarize the phosphoric acid dataset. Segmentation is finalized by a 3D area opening function (cluster size $\leq 3000 \mathrm{px}$ ) in MATLAB which deletes remaining segmentation artifacts. The carbon fiber and binder structure of the GDL was segmented in analogy to the described phosphoric acid segmentation procedure including an additional grayscale level homogenization ${ }^{27}$ preceding the anisotropic diffusion process. Carbon fiber/binder segmentation was performed for a single tomographic dataset at the beginning of the experiment, at low current densities, where minimal amounts of electrolyte are found in the pores of the GDL. From this dataset the porosity information was deduced. Manual alignment of the PA and the carbon datasets yields a PA saturation of the GDL.

The local thickness analysis is a method to derive a pore size distribution ( PSD $_{\text {Pore }}$ ) from binary XTM datasets. It is a computational method and is implemented as proposed by Hildebrand and Rüegsegger ${ }^{28}$ using the Fiji (ImageJ) plugin. ${ }^{29}$ The local thickness $\gamma(p)$ is defined as the diameter of the largest disc which contains the point $(p)$ and which is completely inside a 2D structure which consists of all points $\Omega \subset \mathbb{R}^{2}$ as given in Equation 2:

$$
\gamma(\underline{p})=2 \times \max (\{R \mid \underline{p} \in \operatorname{disc}(\underline{x}, R) \subseteq \Omega, \underline{x} \in \Omega\})
$$

where $(\underline{x})$ is the center and $\mathrm{R}$ the radius of the disc. Local thickness is consequently applied to yield pore size distributions ( $\mathrm{PSD}_{\text {Pore }}$ ) of $2 \mathrm{D}$ slices within the $3 \mathrm{D}$ tomogram. The local thickness method is not restricted to the void space of the GDL to yield a PSD Pore $_{\text {but can also }}$ be applied to liquid droplets of PA to yield particle size distributions (PSD Particle).

A sensitivity analysis for the determined PA volume shows a maximum error of $-4 \%$ to $+11 \%$ for a PA threshold variation of $\pm 2 \%$.

\section{Results and Discussion}

It has recently been observed that under high current density operation $\left(0.8 \mathrm{~A} \mathrm{~cm}^{-2}\right)$, HT-PEFC exhibit extensive acid migration to the anode GDL. ${ }^{10}$ For better understanding of this phenomena, the influence of current density (see Table I) and effect of different membranes (see Table II) on PA migration is examined. XTM measurements were performed in time intervals of $10-30$ min to analyze the dynamics of the migration process. The results are concluded by an analysis and discussion of the influence of the microstructure of catalyst and microporous layer on GDL flooding. 
Table I. Operating parameters and measurement sequences.

Current step

\begin{tabular}{cccccc}
\hline Sequence & Time $[\mathrm{h}]$ & Current density $\left[\mathrm{A} \mathrm{cm}^{-2}\right]$ & Gas flow $\mathrm{H}_{2} / \mathrm{O}_{2}\left[\mathrm{ml} \mathrm{min}^{-1}\right]$ & Cell temperature $\left[{ }^{\circ} \mathrm{C}\right]$ & 160 \\
Gas dew points $\left[{ }^{\circ} \mathrm{C}\right]$ \\
\hline 1 & 4 & 0.2 & $10 / 200$ & 160 & 24 \\
$2 \mathrm{a}$ & 4 & 0.4 & $10 / 200$ & 160 & 24 \\
$2 \mathrm{c}$ & 4 & 0.6 & $10 / 200$ & 160 & 24 \\
& $4 / 4.5$ & 0.8 & $10 / 200$ & 24
\end{tabular}

Table II. Membrane material and PA loading for the current step experiment.

Component Membrane/MEA loading $\left[\mathrm{mg}_{\mathrm{H} 3 \mathrm{PO} 4} \mathrm{~cm}^{-2}\right]$

$\begin{array}{ccc}\text { (i) Pristine PPA } p \text {-PBI } & 36 / 36 \pm 2 & 33 \pm 2 \\ \text { (ii) Low PA PPA } p \text {-PBI } & 23 / 23 \pm 1 & 21 \pm 1 \\ \text { (iii) Film casted } m \text {-PBI } & 24 / 32 \pm 2 & 8 \pm 1\end{array}$

(i) Pristine PPA $p$-PBI

(iii) Film casted $m$-PBI

When phosphoric acid is quantified, it refers to PA droplets in the macro pores of the GDL. The spatial resolution of the imaging (2.3 $\mu \mathrm{m}$ voxel size) prevents the segmentation of PA droplets in the pores of the MPL and the catalyst layer. Additionally, high Pt attenuation and scattering result in unreliable segmentation of PA droplets in the cracks of MPL and catalyst layer. In none of the experiments was PA found in the pores of the cathode GDL and consequently all results are given for the anode side.

In Figure 1a vertical and a horizontal slice of the anode GDL are shown. The location of the horizontal slice is indicated by the dashed line in the vertical slice. In the vertical slice, the different components of the MEA, membrane in the center (light gray), catalyst layers (bright gray/white), the porous GDL (gray: carbon fibers; dark gray: empty pores) and the flow field with three parallel channels, are clearly visible.

The images of Figure 1 depict a condition at high current density where phosphoric acid (light gray) migration to the anode caused the center flow field channel to be completely filled with electrolyte and consequently impairment of the convective gas flux is expected. Diffusive gas transport through the GDL is also hindered due to blockage of macro pores in the GDL as seen in the horizontal slice of the GDL in Figure 1.
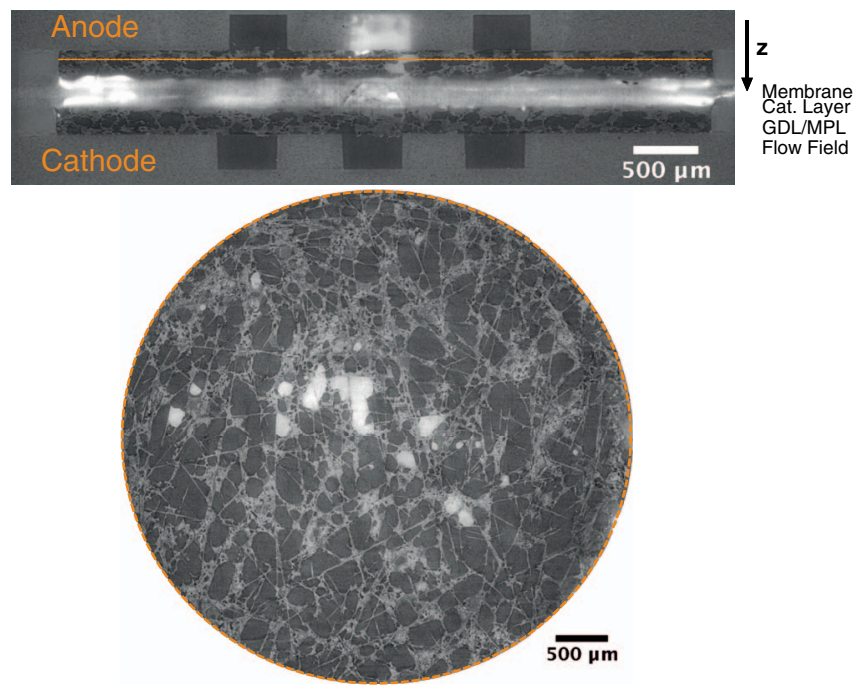

Figure 1. Top: vertical tomographic slice of the MEA (pristine $p$-PBI) at high current density; bottom: horizontal tomographic slice (dashed line in vertical slice indicates the location of the horizontal slice); the different gray scales identify the different MEA components: phosphoric acid droplets in the GDL/flow field: light gray; Platinum catalyst: white; carbon fibers: light gray; empty pores: dark gray).
Figure 2 summarizes the volume of migrated PA in the anode GDL after $4 \mathrm{~h}$ at the given current density for all experiments performed. Due to the hydrophobic coating of the GDL, electrolyte migration into the GDL is considered to be controlled by the buildup of a hydraulic pressure. In this case increasing the current density and, consequently increased hydraulic pressure will eventually lead to a capillary pressure large enough to first fill the pores of the catalyst layer and MPL and then of the GDL and eventually also of the flow field channels. The buildup of the hydraulic pressure with current density becomes evident by the sharp increase in migrated phosphoric acid between current densities of $0.4-0.6 \mathrm{~A} \mathrm{~cm}^{-2}$ (see Figure 2). A deliberate pore size adjustment of the MPL/GDL on the anode side, as done for PAFC, ${ }^{30}$ could eventually also reduce PA flooding in HT-PEFC. The spread of data (c.f. gray shading in Figure 2) indicates heterogeneous microstructure properties of the used GDEs, and it needs to be noted, that due to limited measurement time at the synchrotron facilities no experimental statistics were recorded so far. Interestingly, the maximum PA in the GDL at a current density of $0.8 \mathrm{~A} \mathrm{~cm}^{-2}$ is independent of membrane material and PA loading of the membrane/MEA for the studied parameter range as shown in Figure 2. As a consequence of the GDL flooding, reformate operation (low hydrogen partial pressures) may suffer from diffusive mass transport losses. Based on the present results, this diffusive mass transport of hydrogen through the GDL at high current densities is similar for all three samples.

In Figure 3a detailed temporal analysis of the acid movement to anode GDL and GDL\&flow field channel for the current step protocol $2 c$ (see Table I) are shown for the pristine $p$-PBI MEA (data from Ref.

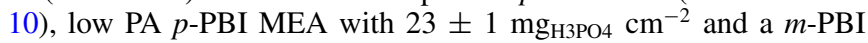
MEA with $32 \pm 2 \mathrm{mg}_{\mathrm{H} 3 \mathrm{PO} 4} \mathrm{~cm}^{-2}$.

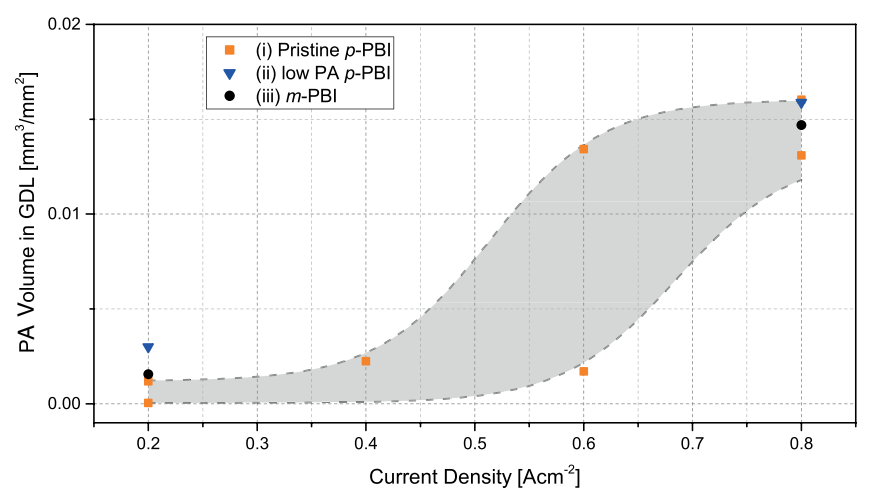

Figure 2. Volume of migrated phosphoric acid in the GDL as a function of current density for all presented experiments (see Table I \& II; $4 \mathrm{~h}$ holding time at each current density). The dashed line acts as a guide for the eye and the gray shading represents the statistical variation in the samples. 

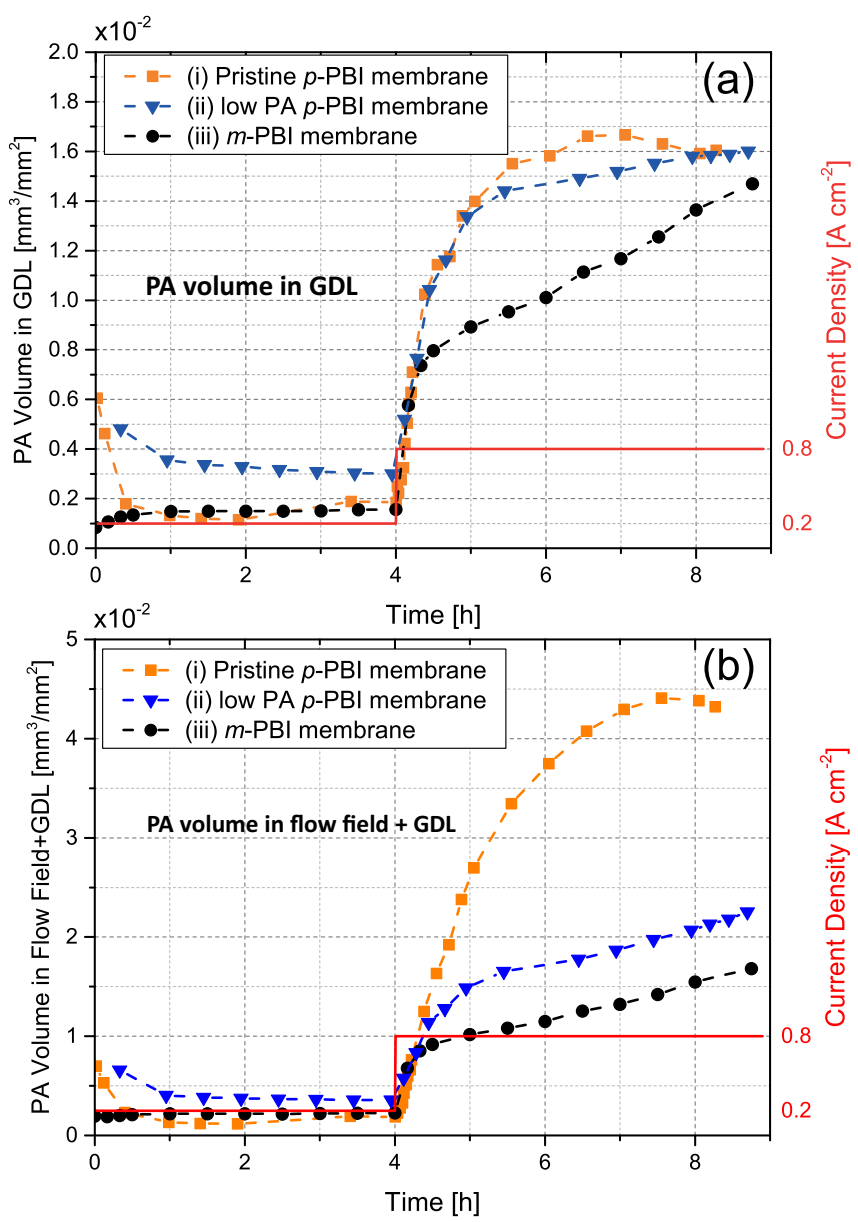

Figure 3. (a) PA volume in the anode GDL and (b) in the anode GDL + flow field during the current step protocol $2 \mathrm{c}$ for the MEAs with (i) $p$-PBI membrane (ii) $p$-PBI with low PA loading and the (iii) imbibed $m$-PBI membrane (details see Table II). Figure partly reproduced from Ref. 20 .

When assembling the fuel cell, the clamping pressure drives small amounts of PA into the GDL which is visible in Figure $3 a(0-2 \mathrm{~h})$. Furthermore, PA is strongly hygroscopic and expands upon exposure to the atmosphere, resulting in this minor filling of GDL macro pores. After about two hours of operation at $0.2 \mathrm{~A} \mathrm{~cm}^{-2}$ in all three samples the amount of PA in the GDL becomes minimal $\left(0.002-0.003 \mathrm{~mm}^{3}\right.$ $\mathrm{mm}^{-2}$ ) and stays constant, equivalent to a GDL saturation level of $<3.5 \%$ for all samples. After four hours at $0.2 \mathrm{~A} \mathrm{~cm}^{-2}$ the current density is increased to $0.8 \mathrm{~A} \mathrm{~cm}^{-2}$ resulting in a comparably fast increase of migrating phosphoric acid in the anode for all three samples.

The MEAs using PPA $p$-PBI membranes exhibit flooding of the GDL with PA up to a volume of $0.016 \mathrm{~mm}^{3} \mathrm{~mm}^{-2}$ after $5-6 \mathrm{~h}$, which corresponds to an average GDL saturation level of $12-17 \%$. Additional PA is then transferred into the flow field channels as shown in Figure 3b. After approximately 4.5 hours, a maximum of migrated acid of $0.043 \mathrm{~mm}^{3} \mathrm{~mm}^{-2}$ is reached for the pristine PA $p$-PBI sample. In the low PA and the $m$-PBI MEAs the volume of migrated acid is still increasing at the end of the current protocol. In previous work ${ }^{10}$ the PA concentration for identical operating conditions was determined to be $96.5 \mathrm{wt} \%\left(\rho_{\mathrm{H} 3 \mathrm{PO} 4}=1.71 \mathrm{gcm}^{-3}\right.$ at $\left.160^{\circ} \mathrm{C}\right)$. This allows for mass quantification of migrated PA and yields values of $28 \mu \mathrm{g} \mathrm{mm}^{-2}$ in the GDL for both PPA processed membranes and a total of 75 and 38 $\mu \mathrm{g} \mathrm{mm}^{-2}$ for the pristine and low PA $p$-PBI sample in GDL and flow field channel together. When considering the total acid inventory of the MEAs (see Table II), the calculation shows that in the two cases 16-20\% of the total membrane acid content has migrated into the anode GDL and flow field channel.
Conclusively it can be stated that the acid migration rate of PPA processed $p$-PBI MEAs has a strong dependence on the PA membrane loading. When considering the derivative of the migrated acid in the linear part of Figure $3 \mathrm{~b}(4.5 \mathrm{~h}-5.5 \mathrm{~h}$ for the MEA with a pristine membrane and $>5.5 \mathrm{~h}$ for the MEA with low PA doping level) an increase of membrane PA loading of about $50 \%$ leads to an increase of acid migration rate by an order of magnitude from 0.04 to $0.54 \mu \mathrm{g}$ $\min ^{-1} \mathrm{~mm}^{-2}$.

The MEA with the film casted $m$-PBI shows a similar behavior upon current density increase as the $p$-PBI MEAs, but changes after 30 min to an almost constant migration rate in the GDL. At the end of the current protocol the $m$-PBI MEA approaches the $p$-PBI membrane values in the GDL. Only negligible amounts of acid $(0.002$ $\mathrm{mm}^{3} \mathrm{~mm}^{-2}$ ) are found in the flow field channels. This can be attributed to the fact that maximum saturation of the GDL is not reached after $4.5 \mathrm{~h}$, at the end of the protocol. For the linear part a migration rate of $0.04 \mu \mathrm{g} \mathrm{min}^{-1} \mathrm{~mm}^{-2}$ is calculated.

Figure $3 \mathrm{~b}$ shows that the migration rates of the MEA with the film casted $m$-PBI membrane and the one with low loaded $p$-PBI membrane $\left(0.04 \mu \mathrm{g} \mathrm{min}^{-1} \mathrm{~mm}^{-2}\right.$ are identical at $\mathrm{t}>5.5 \mathrm{~h}$. Although the membranes in these MEAs have an equal acid loading, the PA/PBI ratio differs by more than a factor of two (see Table II). The acid/backbone interaction is dominated by the protonation of the two available basic pyridinic groups of PBI with $\mathrm{PA}^{31}$ and the polymer-electrolyte interaction in the membrane may be one of the parameters influencing the migration rates. However, when assuming that only two acid molecules interact with the polymer backbone, then still about 80 to $95 \%$ of the acid does not have a close interaction with the backbone in both of these membranes.

As for all examined systems, the PA/PBI molar ratio after $4.5 \mathrm{~h}$ at $0.8 \mathrm{~A} \mathrm{~cm}^{-2}$ is well above the critical value of two PA per polymer unit and therefore, significant amounts of free PA are still present in the molecular pore structure of the membranes. So it must be concluded that the polymer-acid interaction has a negligible influence on the migration rate and that the apparent transference number of hydrogen phosphate and thus the acid migration rate is only determined by the amount of acid in the membranes. Comparing the apparent transference numbers (for $\mathrm{t}>5.5 \mathrm{~h}$ ) of hydrogen phosphate at $0.8 \mathrm{~cm}^{-2}$ and acid loading of the different MEAs pristine $p$-PBI $\left(\mathrm{t}_{\mathrm{H} 2 \mathrm{PO} 4-}=\right.$ $\left.1.1 \cdot 10^{-3}\right)$ and lower loaded membranes $\left(t_{\mathrm{H} 2 \mathrm{PO} 4-}=8.2 \cdot 10^{-5}\right)$ shows that the correlation between apparent transference number and free acid seems to be non-linear with a strong increase with acid loading of the membrane. This correlation must also be a function of the back-diffusion rate of acid from anode to cathode, which is governed by the concentration gradient. An early report ${ }^{32}$ for a cell with $49 \%$ $\mathrm{H}_{3} \mathrm{PO}_{4}$ suggests that the gradient can be substantial and therefore also the back-diffusion rate influencing the apparent transference number. Values for the transference number in concentrated acid are not available in the literature; those in aqueous solutions $\left(t_{\mathrm{H} 2 \mathrm{PO} 4-}^{-} \approx 0.1\right)^{33,34}$ are not comparable, because the proton conduction mechanism in the diluted solution is different, and no back-diffusion is considered.

The different rate behavior for acid migration into the GDL for the low $m$-PBI and the $p$-PBI MEAs shows that the MEA preparation (electrode wetting with PA for $m$-PBI sample, dry hot pressing for $p$-PBI) must have an influence on at least the initial migration rates. Therefore the acid profile in the GDL was investigated for these two MEAs. Figure 4 shows that there is a difference in GDL saturation for the MEA with the low PA $p$-PBI membrane and the MEA having the film casted $m$-PBI during the current step protocol.

At the end of the $0.2 \mathrm{~A} \mathrm{~cm}^{-2}$ step, the samples have the highest PA saturation close to the MPL with a monotonous decrease toward the flow field. After 4.5 hours at high current density $\left(0.8 \mathrm{~A} \mathrm{~cm}^{-2}\right)$, the saturation profile depicts the state of maximum saturation of the GDL. At this point all additional PA in the $p$-PBI sample is directly transferred to the flow field channels and the saturation profile resembles the GDL porosity with an additional saturation maximum close to the flow field due to PA accumulation under the flow field ribs. The $m$-PBI sample exhibits maximum saturation close to the MPL, with a monotonous decrease toward the flow field, showing that the 


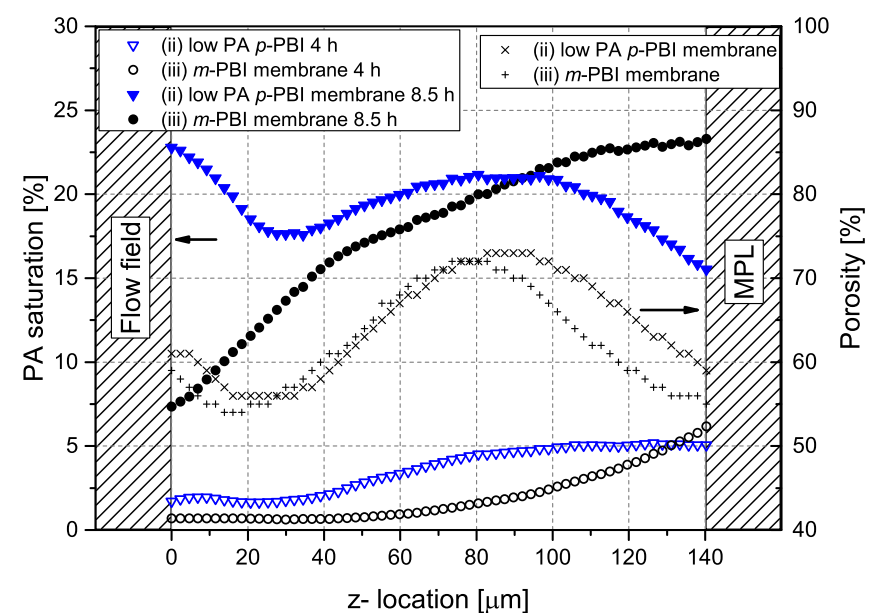

Figure 4. PA saturation and GDL porosity profiles as a function of location within the GDL. The flow field is located on the left and the MPL on the right.

maximum filling is not reached yet. The through-plane GDL saturation profiles indicate an intrinsic difference. For all samples, a continuous pore path of PA is established from the GDL/MPL interface to the flow field channels. In the MEA using a film casted $m$-PBI sample the acid saturation peak at the GDL/MPL interface is attributed to the specific sample preparation, where the electrode was wetted with PA before the experiment. In contrast to the $p$-PBI MEAs, this obviously pre-establishes a significant number of pore paths accessible for migrating PA in this region. The results show that the acid distribution and migration rate is also dependent on the wetted microstructure.

It becomes therefore clear that the microstructure influences PA migration in the porous transport layers. The PA electrolyte is a nonwetting agent for the GDL with its hydrophobic PTFE coating. Consequently, when PA penetrates the porous transport layers at high current densities, a hydraulic pressure is required to push acid into the GDL. Therefore, the path of least resistance for PA is given by the largest pores as defined by the Washburn equation, ${ }^{35}$ which couples the capillary pressure with the pore radius.
Figure 5 analyzes the locations of acid filling of the GDL at the interface between GDL and MPL by means of a local thickness analysis. It illustrates the local pore size distribution ( $\mathrm{PSD}_{\text {Pore }}$ ) for the macropores of the GDL at the GDL/MPL interface. The local thickness analysis was analogously applied to the PA droplets at the interface to get a local size distribution ( $\mathrm{PSD}_{\text {Particle }}$ ) of the acid phase.

Figures $5 \mathrm{a}$ and $5 \mathrm{~b}$ illustrates the $\mathrm{PSD}_{\text {Pore }}$ with relatively large pores in the range of 100-200 $\mu \mathrm{m}$ for both samples scattered over the whole area of the GDL. Figures $5 \mathrm{c}$ and $5 \mathrm{~d}$ shows the distribution of PA droplets with a diameter of more than $65 \mu \mathrm{m}$, which make up 80$90 \%$ (by area) of all PA droplets. The overlay of PA droplets and the GDL structure is illustrated in Figures $5 \mathrm{e}$ and $5 \mathrm{f}$. It shows that for both examined samples some of the largest pores $(>200 \mu \mathrm{m})$ remain empty, while some of the small pores are filled with PA. Conclusively, no clear correlation is established between GDL pore size and PA injection points and the distribution appears random. Of course, in the operando experiment, boundary conditions may not be completely homogeneous. Current density distribution and, hence the electric field driving acid migration may not be ideally homogenous leading to the fact that some of the largest pores are not filled. We think, however, that this is not the main reason and attribute this observation to the microstructural properties of the catalyst layer and MPL. This structure cannot be clearly resolved in the operando experiments due to the blurring by the highly absorbing catalyst layer at the beam energy of $20 \mathrm{keV}$ used for the experiments at the TOMCAT beamline.

The structural characteristics of MPL and catalyst layer have therefore been investigated by means of ex-situ $\mu \mathrm{CT}$ measurements using a classical X-ray tube (not at the synchrotron). At high acceleration voltages (70 kV used here) sufficient contrast for the strongly absorbing Pt containing catalyst layer was obtained.

In Figure 6 a through-plane slice and the respective in-plane slices through the catalyst layer and the MPL are shown. Cracks in the electrode and MPL are clearly visible with significant widths of more than $150 \mu \mathrm{m}$. These so-called mud cracks are the result of material stresses that develop during the drying step of the catalyst layer and MPL inks when evaporating the solvents. Recent imaging work of Lamibrac et al. ${ }^{26}$ on liquid water injection into SGL24BC (a GDL with MPL from the same manufacturer as the material in this study) shows clearly that cracks at the GDL/MPL interface play a significant role in determining the locations of further GDL flooding. The results revealed

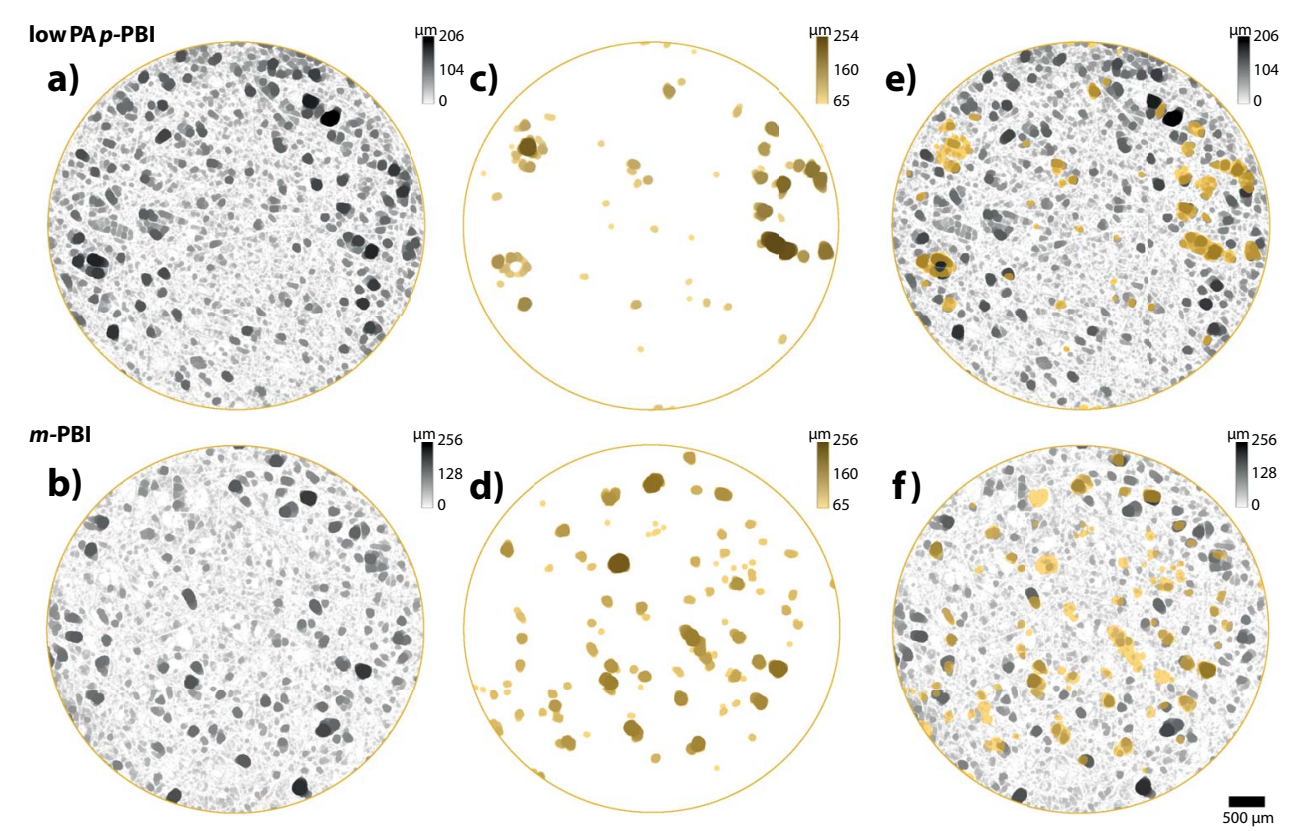

Figure 5. Local thickness analysis for MEAs using low PA $p$-PBI (top row) and film casted $m$-PBI (bottom row); a) and b): pore size distribution (PSDPore) of a GDL slice at the GDL/MPL interface; c) and d): particle size distribution of PA droplets ( $\geq \varnothing 65 \mu \mathrm{m}$ ) in the same GDL slice at high current density; e) and f): overlay of GDL PSD with the PA droplets. 


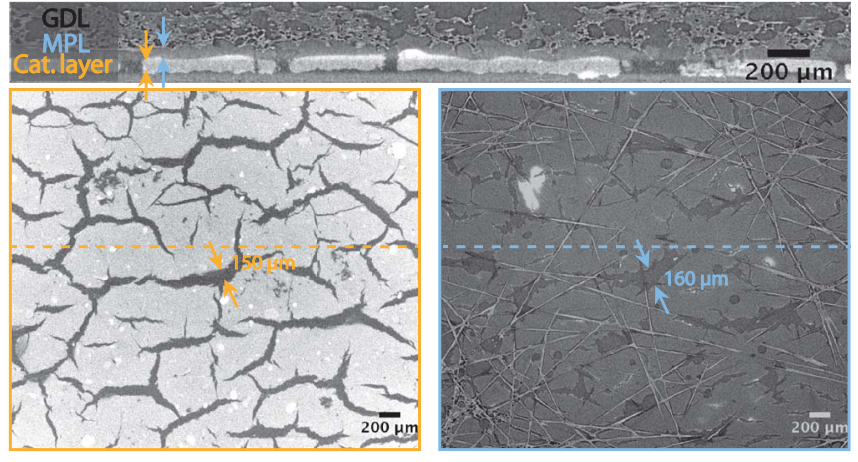

Figure 6. Vertical (top) and horizontal slices (bottom) of the GDE (GDL, MPL and catalyst layer); horizontal slices through catalyst layer (orange highlight) and the MPL (blue highlight). Position of the vertical cut position is depicted by the dashed line.

that water invasion into the GDL occurs only through MPL cracks, showing that the structure of the MPL (and for PA migration possibly also in the catalyst layer) is an important factor for the locations of GDL filling. The mismatch between pore sizes and acid filling shown in Figure 5 must therefore be result of the underlying structure of catalyst layer and MPL cracks.

Considering the liquid invasion mechanism through the MPL/catalyst layer cracks, possible mitigation strategies for PA flooding of the transport layers can be proposed. Specific material preparation processes, such as spray coating, ${ }^{36}$ successfully eliminate deep crack structures that penetrate the entire material. Therefore, the capillary pressure required for PA to penetrate into the GDL can potentially be increased to a point where flooding of the GDL is mitigated or at least reduced.

\section{Conclusions}

Synchrotron based X-ray tomographic microscopy was used to image phosphoric acid electrolyte migration from the membrane into the anode GDL in HT-PEFC during operation at $160^{\circ} \mathrm{C}$. Acid migration is driven by a non-zero transference number of the hydrogen phosphate anion.

The acid migration rate in the interval between 0.2 and $0.8 \mathrm{~A}$ $\mathrm{cm}^{-2}$ shows a sudden increase between current densities of $0.4-0.6 \mathrm{~A}$ $\mathrm{cm}^{-2}$. This indicates that filling of the GDL is based on the buildup of a hydraulic pressure pushing the acid into the hydrophobic porous structure.

To correlate membrane properties and migration rates, MEAs with different membrane materials and PA loadings were investigated. It was found that there is a strong correlation between membrane acid loading and migration rate. When comparing MEAs at $0.8 \mathrm{~A} \mathrm{~cm}^{-2}$ for

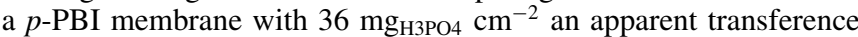
number for the hydrogen phosphate anion of $t_{\mathrm{H} 2 \mathrm{PO} 4-}=1.1 \cdot 10^{-3}$ was found. For MEAs with lower membrane acid loading of 23-24 $\mathrm{mg}_{\mathrm{H} 3 \mathrm{PO} 4} \mathrm{~cm}^{-2}$ the apparent transference number dropped to $\mathrm{t}_{\mathrm{H} 2 \mathrm{PO} 4-}$ $=8.2 \cdot 10^{-5}$. For the MEAs with lower PA loaded membranes (PPA processed $p$-PBI and film casted and imbibed $m$-PBI) no difference in the apparent transference number, was observed, showing that the interaction of the acid molecules with the PBI backbone is not an important parameter influencing the transference number of hydrogen phosphate as long as there is a considerable excess of acid (above a molar ratio of $2 \mathrm{PA} / \mathrm{PBI}$ ) in the membrane.

The microstructure of the porous transport layers and the catalyst layer is an influencing factor for the locations of acid filling of GDL pores. Ex-situ X-ray tomographic microscopy of the MPL and catalyst layer of the used materials revealed an extensive network of cracks which potentially form injection points for migrating PA into the GDL. Hence, using crack free MPLs may help to mitigate or at least reduce flooding of the anode GDL and reduce loss of PA. The influence of GDE microstructure on PA flooding will be subject to future studies where ex-situ experiments with well-defined boundary conditions that can give valuable insight into mitigation strategies.

\section{Acknowledgments}

Financial support by BASF SE and the CCEM project ADMIST, including funding contributions from the Swiss Federal Office of Energy and Swiss Electric Research fund is gratefully acknowledged. We also thank M. Hottiger for precise machining work, T. Gloor for software and electronic support and J. Roth, J. Eller, A. Lamibrac, I. Mayrhuber, M. Toulec, M. Suermann and T. Lochner for support at the TOMCAT beamline.

\section{References}

1. Q. Li, R. He, J. O. Jensen, and N. J. Bjerrum, Fuel Cells, 4, 147 (2004)

2. T. J. Schmidt and J. Baurmeister, ECS Trans., 3, 861 (2006).

3. J. Mader, L. Xiao, T. J. Schmidt, and B. C. Benicewicz, in Fuel Cells II, G. G. Scherer, Editor, vol. 216, p. 63, Springer, Berlin Heidelberg (2008)

4. L. Vilciauskas, M. E. Tuckerman, G. Bester, S. J. Paddison, and K. Kreuer, Nat Chem., 4, 461 (2012)

5. S. Lang, T. J. Kazda, F. Kuhl, and M. J. Hampe, Int. J. Hydrogen Energy, 40, 1163 (2015).

6. K. A. Perry, K. L. More, E. Andrew Payzant, R. a. Meisner, B. G. Sumpter, and B. C. Benicewicz, J. Polym. Sci. Part B Polym. Phys., 52, 26 (2014).

7. R. Zeis, Beilstein J. Nanotechnol., 6, 68 (2015).

8. O. Holderer, O. Ivanova, M. Khaneft, B. Hopfenmuller, W. Luke, A. Majerus, M.-S. Appavou, N. Szekely, M. Krutyeva, and E. Kentzinger et al., ECS Trans. 69, 337 (2015).

9. H. R. Kunz, Electrochem. Soc. Proc., 99-14, 191 (1999).

10. S. H. Eberhardt, M. Toulec, F. Marone, M. Stampanoni, F. N. Büchi, and T. J. Schmidt, J. Electrochem. Soc., 162, F310 (2015).

11. W. Maier, T. Arlt, K. Wippermann, C. Wannek, I. Manke, W. Lehnert, and D. Stolten, J. Electrochem. Soc., 159, F398 (2012).

12. A. Baricci, M. Zago, and A. Casalegno, Fuel Cells, 14, 926 (2014).

13. J. Eller, T. Rosén, F. Marone, M. Stampanoni, A. Wokaun, and F. N. Büchi, J. Electrochem. Soc., 158, B963 (2011).

14. J. Roth, J. Eller, F. Marone, and F. N. Büchi, J. Phys. Chem. C, 117, 25991 (2013).

15. P. Krüger, H. Markötter, J. Haussmann, M. Klages, T. Arlt, and J. Banhart et al., J. Power Sources, 196, 5250 (2011).

16. R. Kuhn, J. Scholta, P. Krüger, C. Hartnig, W. Lehnert, T. Arlt, and I. Manke, J. Power Sources, 196, 5231 (2011)

17. W. Maier, T. Arlt, K. Wippermann, C. Wannek, I. Manke, W. Lehnert, and D. Stolten, ECS Trans., 41, 1413 (2011).

18. T. Arlt, W. Maier, C. Tötzke, C. Wannek, H. Markötter, F. Wieder et al., J. Power Sources, 246, 290 (2014).

19. W. Maier, T. Arlt, C. Wannek, I. Manke, H. Riesemeier, P. Krüger, J. Scholta, W. Lehnert, J. Banhart, and D. Stolten, Electrochem. Commun., 12, 1436 (2010).

20. S. H. Eberhardt, F. Marone, M. Stampanoni, F. N. Büchi, and T. J. Schmidt, J. Synchrotron Radiat., 21, 1319 (2014)

21. S. H. Eberhardt, F. Marone, M. Stampanoni, F. N. Büchi, and T. J. Schmidt, ECS Trans., 69, 591 (2015)

22. J. S. Wainright, J. Wang, D. Weng, R. F. Savinell, and M. Litt, J. Electrochem. Soc., 141, L121 (1995).

23. L. Xiao, H. Zhang, E. Scanlon, L. S. Ramanathan, E. Choe, D. Rogers, T. Apple, and B. C. Benicewicz, Chem. Mater, 17, 5328 (2005).

24. M. Stampanoni, A. Groso, A. Isenegger, G. Mikuljan, Q. Chen, A. Bertrand, S. Henein, R. Betemps, U. Frommherz, and P. Böhler et al.. Developments in XRay Tomography V, edited by Ulrich Bonse, Proc. of SPIE, 6318, 63180M (2006).

25. F. Marone and M. Stampanoni, J. Synchrotron Radiat., 19, 1029 (2012).

26. P. Perona and J. Malik, IEEE Trans. Pattern Anal. Mach. Intell., 12, 629 (1990).

27. A. Lamibrac, J. Roth, M. Toulec, F. Marone, M. Stampanoni, and F. N. Büchi, $J$. Electrochem. Soc., 163 , F202 (2016).

28. T. Hildebrand and P. Rüegsegger, J. Microsc., 185, 67 (1997).

29. R. Dougherty and K. H. Kunzelmann, Microsc. Microanal., 13, 1678 (2007).

30. T. Murahashi, in Encyclopedia of Electrochemical Power Sources, J. Garche, C. K. Dyer, P. T. Moseley, Z. Ogumi, D. A. J. Rand, and B. Scrosati, Editors, p. 564 (2009).

31. Q. Li, J. O. Jensen, R. F. Savinell, and N. J. Bjerrum, Prog. Polym. Sci., 34, 449 (2009).

32. J. T. Lundquist and W. M. Vogel, J. Electrochem. Soc., 116, 1066 (1969)

33. M. Kerker, H. E. Bowman, and E. Matijević, Trans. Faraday Soc., 56, 1039 (1960)

34. M. Selvaratnam and M. Spriros, Trans. Faraday Soc., 61, 360 (1964)

35. E. W. Washburn, Phys. Rev., 17, 273 (1921).

36. F. Mack, M. Klages, J. Scholta, L. Jörissen, T. Morawietz, R. Hiesgen, D. Kramer, and R. Zeis, J. Power Sources, 255, 431 (2014) 